\title{
Wildlife Resources, Conservation Challenges and Management Strategies in Ethiopia: A Review Paper
}

\author{
Ziyad Jemal $^{1^{*}} \quad$ KedirAbdurahman $^{2}$ \\ 1.Oromiya Forest and Wildlife Enterprise,Ethiopia \\ 2.Madda walabu University; Bale Robe, Ethiopia
}

\begin{abstract}
Ethiopia is rich country in biological diversity; exclusively large mammals. Protected areas are the main focus for the maintenance of wildlife resources and contribute for economic developments of a nation. However, they face significant challenges in meeting human and wildlife needs. Although most communities viewed protected areas and wildlife favorably, the lack of benefits limited local willingness to encourage conservation work. Failure to conserve protected areas will have direct consequences for biodiversity conservation and will prevent the sustainable use of wildlife as a development option. Therefore mitigation and preventive strategies for conservation measure is needed in order to manage wildlife in sustainable manner.
\end{abstract}

Keywords: conservation, management strategies, wildlife resources

DOI: $10.7176 /$ ALST/72-01

Publication date:March $31^{\text {st }} 2019$

\section{Introduction}

Ethiopia is characterized by a wide range of ecological, edaphic and climate conditions that account for the wide diversity of its biological resources both in terms of flora and fauna (IBC, 2009). In response to the climatic diversity, a lot of species are only present in specific areas of the country, where their climatic requirements are met. Due to its high elevation levels that areexceptional in Africa, there is high degree of endemism in Ethiopia's mountain proportionately to the total number of species in the country (Yalden and Largen, 1992).

Ethiopia is one of the most diverse mammalian faunas in Africa and the great attractions of its wildlife heritage. The country has established many protected areas.National Parks and Sanctuaries, which are referred to as principal conservation areas (LeykunAbune, 2003). In spite of the rich wildlife resources in Ethiopia, due to enormous habitat degradation and fragmentation many wildlife species including the endemics are threatened (ZerihunGirma, 2012). Mainly, expansion of agriculture, livestock encroachment, deforestation, illegal fire and increasing human population has been often cited as the major cause of bird's habitat degradation, fragmentation and loss in Ethiopia ultimately affecting the survival of wildlife (Sekercioglu, 2012).

Most issues of habitat and wildlife devastationare complex, location specific, and involve several and often conflicting groups of people, creating a challenge to biodiversity conservation that can only be met with a solid understanding of the true pressures and influences behind behavior patterns towards resource use (DemekeDatikoand Lemma Tiki, 2017). So the objective of this paper was to review wildlife resources, conservation challenges and management strategies in Ethiopia.

\section{Wildlife potentials of Ethiopia}

One-fourth of Africa's wildlife is found in Ethiopia and comprised 2970 species of animals. Of the animal species 320 are mammals of which 36 are endemics; 926 bird species consisting of 24 endemics, 1,249 arthropods with 11 endemics, 200 fish with 40 endemics, 202 reptiles with 17 endemics and 73 amphibians with 30 endemic species (EBI, 2014 and WeldemariamTesfahunegny, 2016).

Between 6,500- 7,000 are higher plants consisting of $12 \%$ endemics (EBI, 2014).The vegetation of the Ethiopia categorized under five recognized biomes: Sudanian, Congo-Guinean, Sahel arid zone, Somali-Maasai, and the Afrotropical and montane. These can be further sub-divided into ten broad ecosystems: Afroalpine and Subafroalpine Ecosystem, Montane Grassland Ecosystem, Dry Evergreen Montane Forest and Evergreen Scrub Ecosystem, Moist Montane Forest Ecosystem, Acacia-Commiphora Woodland Ecosystem, CombretumTerminalia Woodland Ecosystem, Lowland Tropical Forest Ecosystem, Desert and Semi-desert Scrubland Ecosystem, Wetland Ecosystem and Aquatic Ecosystems (EBI, 2014).

Traditionally Ethiopia is known by seven distinctive and large endemic mammals that why it is represented as "Home of the Unique Seven". Ethiopian wolf (Canissimensis), Mountain nyala (Tragelaphusbuxtoni), Walia ibex (Capra walle), Menelik's bush buck(Tragelaphusmenilik), Swayne's hartebeest (Alcelaphusbuselaphusswaynei), Gelada baboon (Theropithecus gelada) and Bale monkey (Chlorocebusdjamdjamensis) were those seven large mammals and the rest (83.9\%) are smaller ones including two, nine and fifteen species of bats, insectivores and rodents, respectively (Tefera, 2011).

Ethiopia has some of the most magnificent national parks and wildlife resources in Africa which have both national and global value. 


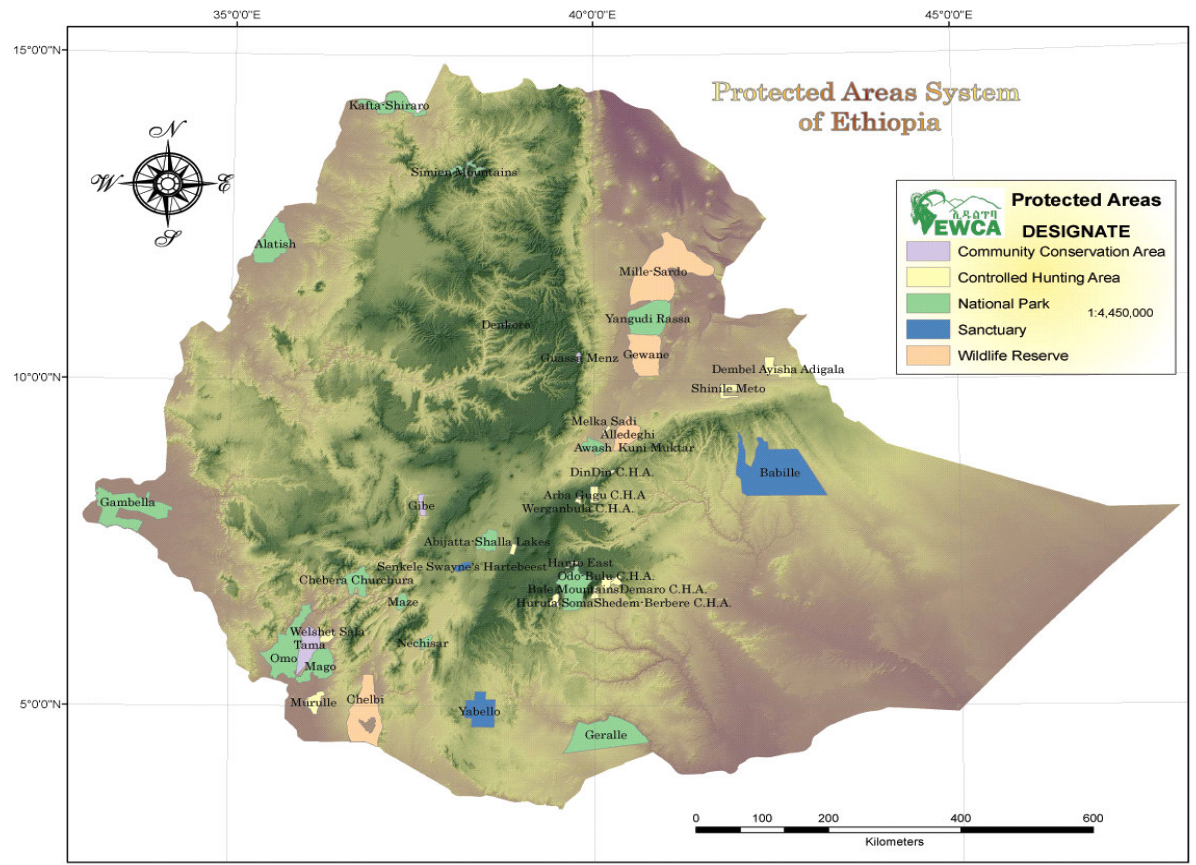

Figure 1: The map of Ethiopia showing Protected Areas of Ethiopia (source, Young 2012).

For example in and around Abijata-Shala Lakes National Park (ASLNP); there are about 300 species of birds and ASLNP is also the home for varied and populated species of wildlife; among these Grants Gazelle(Nangergranti), greater kudu(Tragelaphusstrepsiceros), lesser kudu(Tragelaphusimberbis)and warthogs(Phacochoerusafricanus) were the dominant mammals' species(GirmaMengeshaet al., 2011).

These different species of wildlife are protected and managed in different site of conservation areas (Yarrow, 2009). There are 58 protected forest priority areas, 21 national parks, 2 wildlife sanctuaries, 3 wildlife reserve areas, 6 community conservation areas, 2 wildlife rescue centers, 20 controlled hunting areas, 2 botanical gardens and herbariums and 4 biosphere reserves (Young, 2012).According to Institute of Biodiversity Conservation (2009), protected areas covers $19.05 \%$ of the country. However according to Ethiopian wildlife conservation authority (2012),protectedareas of Ethiopia constitutes $14 \%$ of area of the country. The variation in proportion of Protected Areas emanated from continuing re-demarcations of the Protected Areas that have been conducted since 2009.

In Ethiopia different ecosystems and diverse topography provide a wide spectrum of habitat type for many fauna and flora species. Ethiopia accounts $70 \%$ and $80 \%$ of all the afro-tropical lands above 2,000 masl and3,000masl of all the lands (EWCA, 2012). In the southeast part of the country Bale Mountains National Park has some of the largest areas of continuous and Afro-montane forest habitats in Africa followed by the fragmented Afro-alpine ecosystem in the north western highland (Beyer et al., 2010). Bale Mountains National Park covers about $1990 \mathrm{~km}^{2}$ followed by Arsi mountains national park in Arsi zone of oromiya regional state in Ethiopia which covers about $1000 \mathrm{~km}^{2}$. The study of Beyer et al. (2010) also indicated that the coverage of others Afro-alpine areas are in northern Ethiopia; Simien Mountains National Park $\left(960 \mathrm{~km}^{2}\right)$, South Wollo $\left(1220 \mathrm{~km}^{2}\right)$ and the fragmented North Wollo areas together cover $1150 \mathrm{~km}^{2}$ (Fig.1).

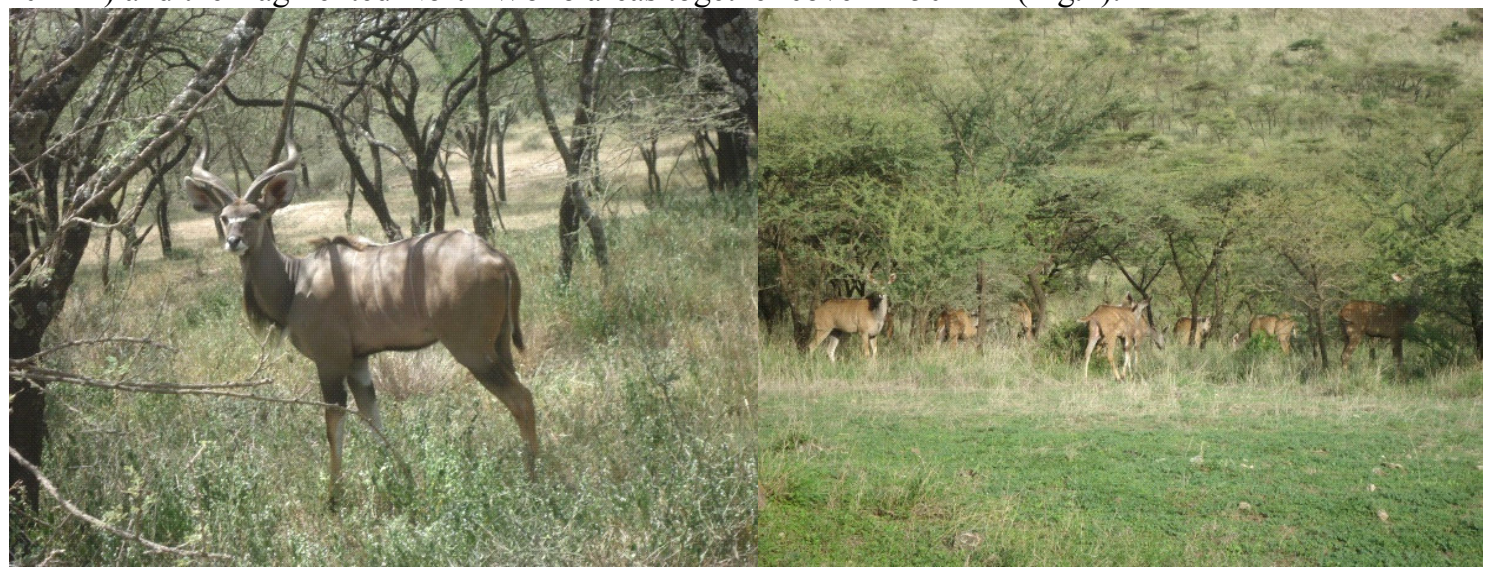

Figure 1 : Greater kudufrom Arsi Mountains National park Dera dilfekar block (Photo by: Ziyad J.) 


\section{Community Attitude towards Wildlife Conservation}

The interaction between human being and nature was took place before million years ago when human being was created. Their relationships have been enlarged and more intense during the hunt and gathering (Yalden and Largen, 1992).In the recent past, before the expansion of wildlife promotion and education, some people also defined "wildlife" is only large mammals; such as elephants, lions, cheetah, hyena, leopard, buffalo and other related species. However, wildlife refers to the variety of all living organisms inhabiting in the wild, at the genetic, species and ecosystem levels on earth (AlamnehAmare, 2015).

The key approach to habitat conservation across the world has been the establishment of protected areas. Although the value of large intact sections of unexploited habitat is priceless for ensuring survival of biodiversity, this form of conservation has been burdened with complications (Young, 2012).Protected areas in the past tended to neglect the human aspect of ecosystems and were often established without regard to socioeconomic, cultural, and land tenure issues of the surrounding communities (Stanley et al., 2014). Some parks were created through taking away of land from people who had inhabited the region for centuries, and in various locations local communities were uninformed that a park had even been created in their forest. Local people continued or increased their use of the resources protected in the reserve, either out of necessity or in anticipation of a loss of accessibility, increasing the conflict between the park and the people (Stephens et al., 2001). Other parks continue to exist only on paper, with few administration staff and insufficient budgets further hindering conservation efforts

The study by YosefMamo (2014), on Bale mountains national park in Ethiopia indicated that $83 \%$ of respondent agreed on lack of benefit on distribution.

Protected areas alone however, cannot ensure the protection of all the Earth's biodiversity. Mutually supportive relationships between communities and nearby protected areas are critical to the long-term success of conservation efforts (Hobbs, 2002). In sub-Saharan Africa, many protected areas were first created during colonial times as hunting grounds or parks for European elites, with little or no regard for the needs or desires of local communities (Anderson and Grove, 1987; Neumann 1998; Adams 2003). Conflicts over land tenure and resource use can create conflicts between local communities, protected area staff, and conservation goals (Newmark et al., 1994; Lilieholm and Romney, 2000; Whitesellet al., 2002).

Due to growing populations, boundary conflicts and repeated drought these areas face many challenges. A chronic and growing issue for Ethiopia's largely pastoral rural people is local access to grazing lands (Zelelem andWilliams, 2005). As in other parts of the developing world, increased concern over the burden that conservation often places on local communities has led to efforts to incorporate development goals into conservation practices (Hulme and Murphree, 2001).

\section{Major Conservation Challenges \\ Humanwildlife conflict}

In developing countries like Ethiopia Human-wildlife conflict is a major concern of most people living around to protected areas due to their subsistent live (Wolff, 1961 andTefera, 2011). It arises when increasing the needs of human populations overlap with protected areas and results scrambling for resource.

Presently due to anthropogenic effects these protected areas are extremely threatened. As the population increases, there is an increasing demand for space and resource utilization and affects wild animal's habitat on the protected areas. The study of MeseleYihune (2008) onSimien Mountains National Park indicated that the population of Walialbex (Capra walie) and their habitat has decreased due to agricultural expansion. MeseleYihune (2008) also noted that the endemic gelada baboon (Theropithecus gelada) was the main causes of conflict with local communities because of their farmlands in these villages were located close to the habitat of gelada baboons. Thestudy ofTewodrosKumsa(2006) in the senkelle wildlife shows that the habitat of the sanctuary was currently shrunken from $200 \mathrm{~km}^{2}$ to $54 \mathrm{~km}^{2}$, as a result the population of Swayne's hartebeest (Alcelaphusbuselaphus)decreased from 3000 individuals during 1972 to 800individuals due to population growth and agricultural expansion.

\section{Deforestation and Unsustainable harvesting of natural resources}

Deforestation resulting land degradation is the global threats for several wild animals with its natural habitat and affects the wild animal's life style in their preferred habitats. The forest cover of Ethiopia has been approximately $40 \%$ of its land a century ago but now has declined to only 3\% (Masanja, 2014). The human population around most protected areas over the years has been changing in terms of its size, density and livelihood strategies (Masanja, 2014). Uncontrolled logging, illegal charcoal production and fuel wood collection are some of the major causes of deforestation that directly influence large mammal's habitat, where tourism is dependent (DemekeDatiko and Lemma Tiki, 2017). Moreover, such activities impose to decline the scenic beauty of the protected area which also affects tourism and wilderness.

Extensive expansion of arable land, depletion of woody vegetation, reduction of rangelands, soil erosion 
and siltation of water bodies and loss of soil productivity attributed to cause negative impacts on faunal populations (Kidegheshoet al., 2001). According to the study conducted bySinclair 1995 in Serengeti, Tanzania Roan antelope (Hippotragus equines) is reported to be locally extinct in many areas of the ecosystem due to the loss of its Combretumdominated habitats.

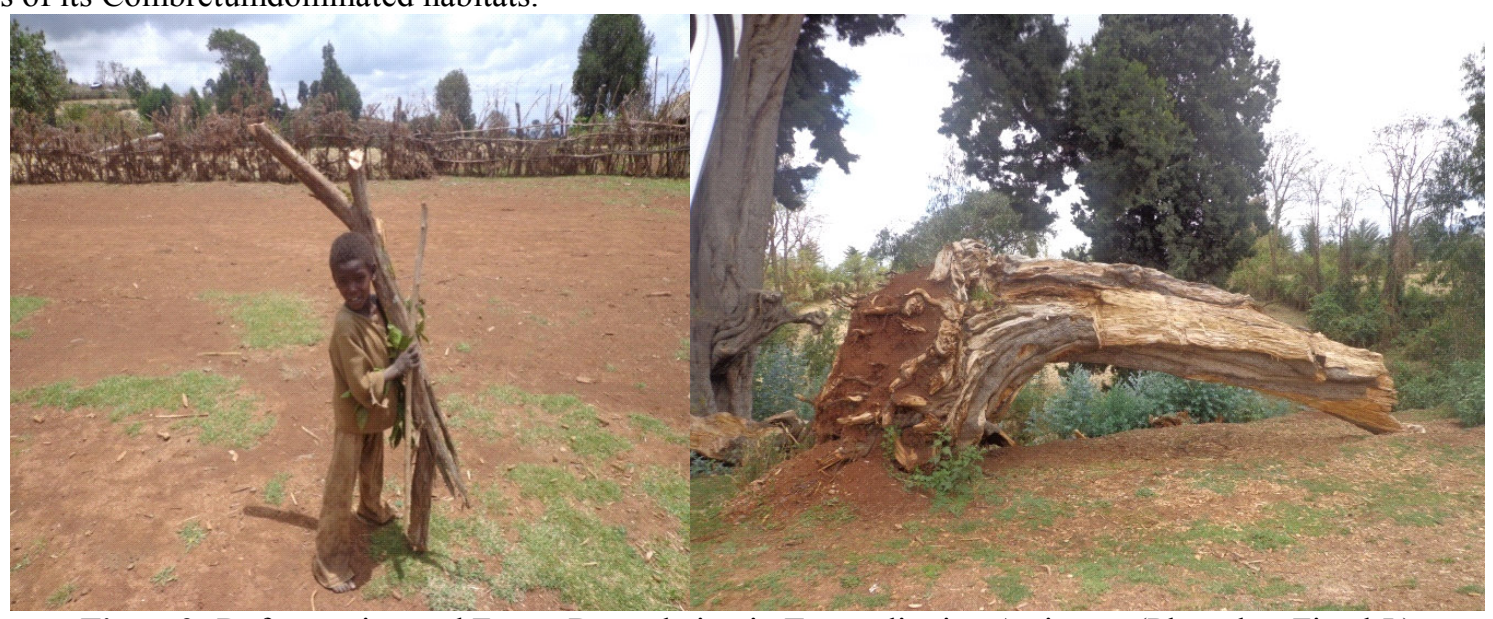

Figure2: Deforestation and Forest Degradation in Tanna district, Arsi zone (Photo by: Ziyad J.)

\section{Hunting}

Ethiopia is a country exceptionally high in globally unique biodiversity; however wildlife populations throughout the country have been reduced to a fraction of what they were due to a number of causes, including hunting (DemekeDatiko and Lemma Tiki, 2017).This appears to have several root causes, including cultural traditions, subsistence, and buffers during famines and reprisal against government (HUSA, 2012).

Several national parks and controlled hunting areas are spread across the country, but the institutional and financial capacity for protected area management is low and benefit sharing mechanisms with communities are lacking (HUSA, 2012).Hunting management is highly focused on revenue derived from concessions and trophy fees, particularly those targeting the endangered Mountain Nyala the world's rarest mammal still subject to commercial harvest (HUSA, 2012).However, over exploitation of wildlife resources negatively affects the population of many large animals and habitats, where tourists recreate.

Poaching and illegal wildlife trade activities in and around the park, as well as the unwise use of natural resources have been the major problems facing the park and have led to the extinction of some fauna species (TewodrosKumsa, 2006).In some parts of Ethiopia like Gambella, Ethiopian Somali and Afar areas, poaching has been practiced for income generation and agricultural practices (DesalegnWana, 2008).Historically, as distinguished by "Stephenson (1978), abundant population including Oryx (Beisaoryx), Swayne's hartebeest (Alcephalusbusephalusswayeni), Buffalo (Synceruscaffer), Giraffe (Giraffacamelopardalis) and Lion (Pantheraleo) in theAbijatashalla lakes national park but currently these animals have been eliminated through illegal hunting and replaced by other species.

\section{Overgrazing and Illegal Settlement}

The common problems in most African countries are conflicts over natural resources (Stewart et al., 2002).In both arid and semi-arid ecosystems overgrazing by domestic livestock is the major cause of land degradation((Perveenet al., 2008 and Huang et al., 2007).According to the study conducted byNdibalema (2010) in Serengeti ecosystem, the increased human settlement in the area has contributed greatly to lack of free space for animal movements as it can be converted to increased human settlements. High levels of livestock grazing may affect the quality of the wildlife habitat (Vial et al., 2011).

For example in the case of Ethiopia Livestock is present in most of the legally protected terrestrial areas of Omo national park, irrespective of their legal status (African parks, 2005).This has also resulted in shrinkage of the buffer zone area of the park. The report of African parks in (2005) also revealed that the integrity of Omo national park and Mago national park has partly destroyed due to encroachment and now signifies the main challenge for the developing wildlife sector in Ethiopia. 


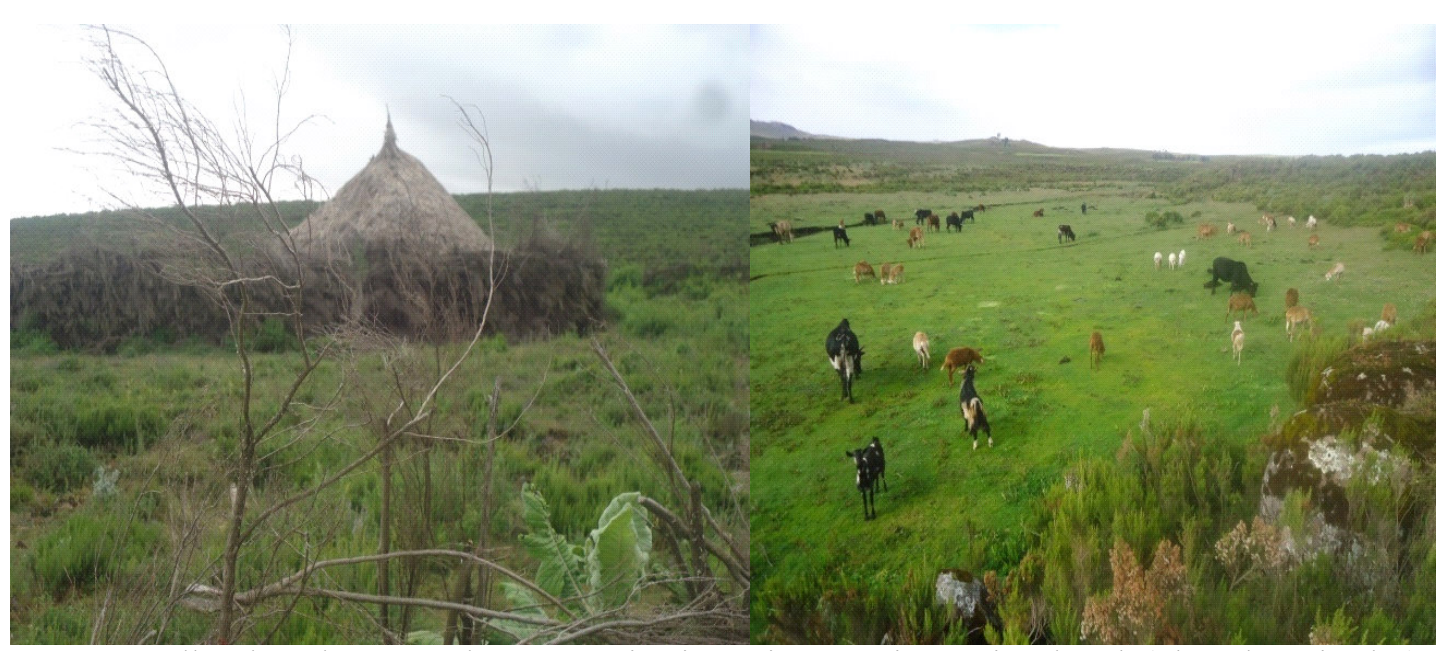

Figure 3: Illegal Settlement and Over Grazing in Arsi Mountains National Park (Photo by: Ziyad J.)

\section{Wildlife Disease}

For improved wildlife management Wildlife disease management is the most important issue especially for threatened and endangered species (Riley et al., 2002). Other wildlife species, domestic animals and humans may be affected by some pathogens

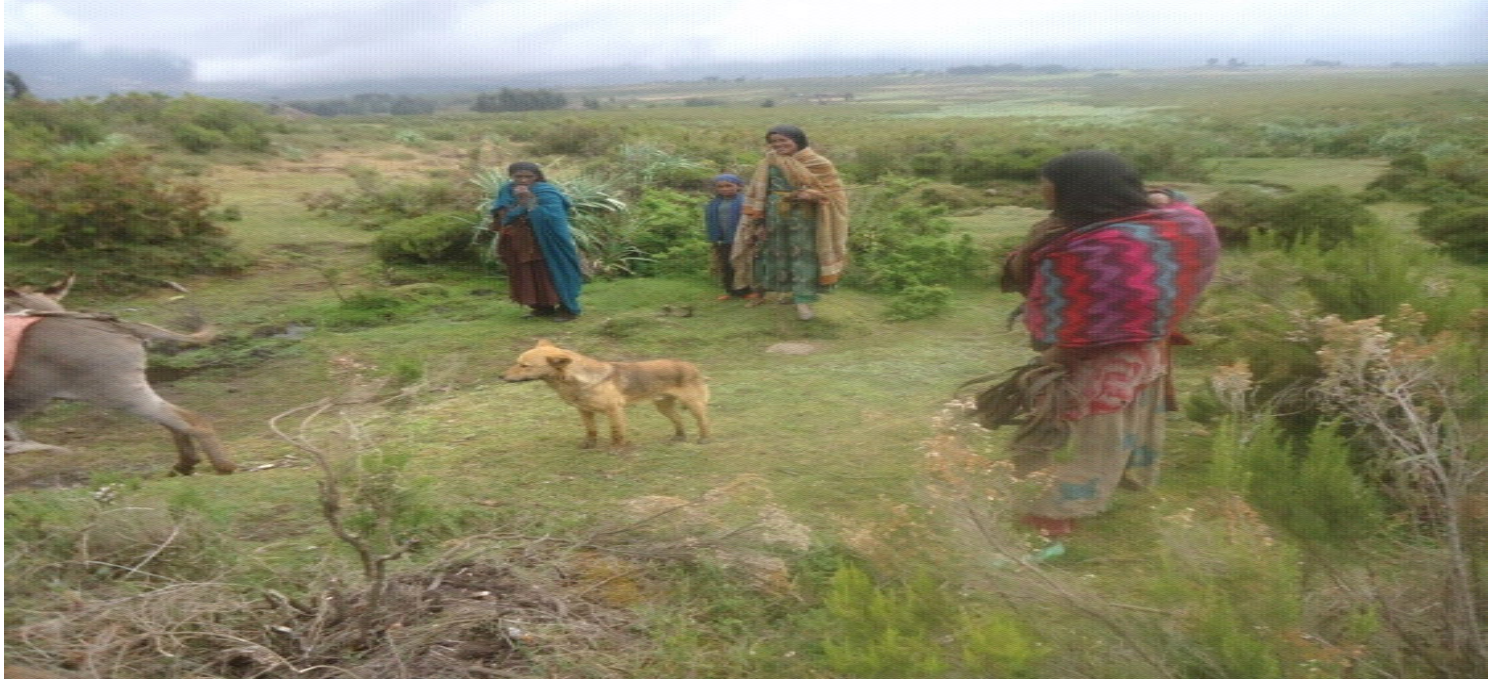

Figure 4: Dog in Wildlife Area; Chilalo- GalamaArsi zone (Photo by Ziyad J.)

Severe diseases are simply transmitted by wildlife to domestic animals and possibly to humans (e.g. rabies). Rabies possesses a serious risk for populations of rare carnivores and is possibly the most dangerous disease that may affect the Ethiopian wolf (AnagawAtickem et al., 2009). Twenty-one of 34 species of canid have been reported to kill domestic animals (AnagawAtickemet al., 2009). Parts of infected carcasses can be opening up, dismembering and dispersing by Scavengers and predators, such as spotted hyenas, jackals, lions and vultures and also play a role in disseminating pathogens (Marino et al., 2006).For example the study by Woodroffeet al. (2007) revealed that, predatorscan ingest anthrax spores together with carcass tissue and the spores are then widely disseminated in the predators' faeces. In the late 1960s again also the African buffalo played the key role as maintenance host of foot-and mouth disease. Wildbeestplayedthe important role in the maintenance and seasonal shedding of alcelaphine herpesvirus-1 (Bengiset al., 2002).Bovine tuberculosis (TB) is also a serious disease of cattle which can be transmitted to people. During the 1930s over 2500 people died each year from this disease in Great Britain alone (Woodroffeet al., 2007).

\section{Management strategies}

Management in a broader term is a science and art disciplines for planning, organizing, leading and controlling activities. Wildlife management is a science and art of applying ecological knowledge in the management of wildlife population in a manner that strike a balance between the need of wildlife population and the needs of people (Bolen and Robinson, 2003).

According to Adams et al. (2007) human wildlife conflict exists when the needs and behavior of wildlife 
impact negatively on the goals of human beings. It occurs when growing human populations overlap with established wildlife territory, creating reduction of resources or life to some people and wild animals. Human wildlife conflicts are highly variable and there is no single management option or solution that can resolve the problems. Management techniques are only cost-effective if the cost of implementing the technique is less than the value of the damage, taking into account the fact that a short period of active management may have a continued effect, by instating longer-term protection of crops or herds (Adams \& Hutton, 2007).

Based on the characteristics of conflict, Treves and Karanth (2003) stated that major management possibilities are human management, production management, animals' management and environmental management.

\section{Human Management \\ Community awareness}

In human management techniques the first step is to raise people's awareness that they are in a wildlife area and of the potential consequences; living, working or travelling in areas with large carnivores calls for preparedness (Paris, 2006).Education and training activities could be directed towards disseminating innovative techniques, building local capacity for conflict prevention and resolution, and increasing public understanding of humanwildlife conflict.

Educating rural villagers in practical skills would help them deal with dangerous wild animal species and acquire and develop new tools for defending their crops and livestock (Quigley and Herrero, 2005).Environmental awareness should include ecosystems, carnivore behavior, risk factors and managing activities to reduce human vulnerability. And on the other hand different studies in different parts of the world shows that support for wildlife conservation was positively correlated with the level of education of the individual community. Forexample the research conducted by DemekeDatiko and Lemma Tiki on challenges of human settlement on wildlife in Bale Mountains National Park, Southeast Ethiopia in 2017 indicated that educated peoples supported protected areas more than those with no formal education.Gadd (2005) also observed a similar situation in a study of people's attitudes towards the wildlife in Kenya.

\section{Waste management}

Elephant Pepper Development Trust (2006) reported that waste management around wildlife areas is another key mechanism to reduce human wildlife conflict. The impacts of waste on our health and the environment are only just becoming apparent (Mudgalet al., 2011).The state of plastic waste is notoriously hard to measure. There are several chemicals within plastic material itself that have been added to give it certain properties such as Bisphenol A, phthalates and flame retardants. These all have known negative effects on human and animal health, mainly affecting the endocrine system (Barnes et al., 2009).Research has indicated that some species or developmental stages are more vulnerable to ingestion of plastic waste and the toxic effects of the chemicals associated with it. In the marine environment, the most well documented impacts are entanglement and ingestion by wildlife (Sheavly, 2005).There is different studies on the impacts of wastes on wildlife in terms of entanglement and ingestion. Murray and Cowie (2011) investigated plastic ingestion by Nephropsnorvegicus (langoustines). They found 81 per cent of their sample contained plastics, mainly in the form of filaments, but also in tightly tangled balls of plastic strands.

On the other hand due to improper waste management wild animals may be attracted to human settlements by the availability of human foods (Sheavly, 2005).

\section{Compensation}

Compensation can be in the form of direct compensation and indirect compensation (ecotourism, benefitsharing). The payment of compensation in the event of loss is usually confined to a specific category of loss, such as human death or livestock killed by predators. All are designed to increase the level of tolerance among for damaged properties so as to decrease human wildlife conflict (Muruthi, 2005).

The compensation mechanism must balance the costs of damage incurred by victims with benefits provided by income-generating activities or by state agencies or non-governmental organizations (NGOs). Realistically speaking there is no easy way that compensation could be paid for crop damage or livestock losses. It would, however, be possible to envisage compensation for injury and loss of human life (Baldus, 2005).

Another form of compensation is indirect compensation systems that rely on giving out licenses to exploit natural resources, through tourism, legal hunting, collecting fuel wood, timber, mushrooms and fodder. This type of compensation scheme, is also known as the "settlement of rights" to use natural resources.

The study in India by Sekhar (1998) revealed that this type of compensation appears to be a more practical solution than monetary payment. Indeed, the benefits derived from the legitimate use of natural resources influence the attitudes and perceptions of rural residents.

Tourism would increase people's tolerance for some stock losses (Woodroffeet al., 2006).Wildlife tourism 
is rarely compatible with intensive livestock husbandry, but it is a management practice that encourages the coexistence of wildlife and people. It can only be successful in areas with enough wildlife to support the activity and enough employment opportunities. In some of these areas, cattle ranchers and communities are realizing that there is more money to be made in keeping wildlife alive (Conover, 2002). Tourists prefer to harvest a few adult male animals by trophy hunting, which generates revenues and encourages peoples to conserve wildlife, rather than use problem animal controls such as poisoning or trapping, which cost money and provides no revenue for rural communities (HUSA, 2012). For example the research conductedin Ethiopia by ZelealemTefera and Williams (2005) around Menzguassa community conservation area, grasses are collected from the wild by communities and used for cattle fodder. In addition communities receive a financial incentive from ecotourism; this increases their tolerance of wildlife conservation (ZelealemTefera and Williams, 2005).

\section{Voluntary relocation}

Where alternative land and incentives are available, the voluntary relocation of local communities to areas offering better access to natural resources and improved socio economic opportunities can offer an adequate solution to managing human wildlife conflict (Madhusudan, 2003). In fact, resettlement schemes aimed at preventing the overlap of wildlife and people can be successful in the long run if some essential assumptions are met: the villagers must gain substantial benefits, such as better access to resources; they should be relocated to an area where the risk of losing property is lower; and they should not face any political, social and cultural opposition (Treves and Karanth, 2003). When socially acceptable, this option is expensive. For example, donors paid approximately US\$16 million to relocate the 6000 people living inside the Limpopo National Park in Mozambique (Hofmeyr, 2004).

\section{Production management}

The major methods used to protect human production against the adverse effects of wildlife were intensifying human vigilance, guarding animals and fencing (Ogadaet al., 2003).

\section{Intensifying human vigilance}

Vigilance is an important component of crop or livestock protection to reduce human wildlife conflict. The fear of humans normally dissuades animals from committing damage. Guarding herds and taking steps to actively defend them are essential features of animal husbandry. Where herdsmen are present, the rate of depredation is generally lower than in free-ranging herds (Breitenmoseret al., 2005).

On the other hand watchtowers providing good vantage points, built around cultivated fields, can increase the farmers' chances of being alerted to the presence of potentially harmful wildlife before damage has occurred (Hanks, 2006).

\section{Guarding animals}

Guard animals provide an alternative to a herder monitoring a flock, which is labor intensive, time-consuming and costly. To be successful, a guard animal must bond with the animals they are to guard. This bonding, combined with the guard animal's natural aggression toward predators, can make a guard animal an effective protector. Dogs can be effective in protecting homesteads and livestock from attack by predators. The dogs are trained to alert people to the presence of predators, rather than chasing predators(Hawley, 2009). These dogs are raised from puppyhood with sheep or cattle and live with the herd full-time. Several new training aids are now available to the dog handler including "shock collars" to provide stimuli to the animal in obedience training and are used in conjunction with whistles and global positioning system (GPS) collars in the event of animals becoming lost (La Grange, 2005).

A study carried out between January 1994 and November 2001 of domestic dogs accompanying herds in 117 Namibian farms, showed that guard dogs were successful in terms of reducing livestock losses, with 73 percent of responding farmers reporting a significant decline in losses since they acquired a dog (Gehringet al., 2010).

\section{Fencing}

If properly designed, constructed and maintained, fences can be almost completely effective in preventing conflict between people and wild animals and also prevent the transmission of certain endemic contagious diseases such as foot-and-mouth disease, African swine fever and theileriosis(Murphy, 2007).

The establishment of control areas, game-proof fences, sanitary cordons and movement control to separate wildlife from domestic livestock has frequently given the best results. This method has generally been used in countries with an advanced land-use policy where nomadic pastoralist is not practiced (Ogadaet al., 2003).Although the introduction of fencing is a good way to manage human-wildlife conflict; it also brings a number of environmental and economic disadvantages and is never 100 percent efficient. In Zimbabwe, in the 
areas neighboring the Sengwa Wildlife Research Area, livestock are still attacked even though the reserve is fenced and livestock are penned in fortified enclosures at night (Ogadaet al., 2003). This is because baboons, lions and leopards can pass through the reserve fence and jump into the enclosures. Improving fences with the addition of a roof (chain link ceilings for instance) would substantially reduce economic losses (Butler, 2000).

The major types of fences used throughout Africa for various purposes were; traditional barriers, artificial fences and Electric fencing were the major one.

Traditional barriers: Plant hedges of various spiny cacti (e.g.Caesalpiniadecapetala and species of Euphorbia, Opuntia and Agave) have the advantage of being a low-cost solution, effective against both carnivores and ungulates. On the other hand, they are slow to establish, do not deter baboons and elephants, and are often made of exotic species which can spread uncontrollably (Hanks, 2006).

Artificial fences: Fences constructed using strong material such as galvanized steel wires protect crops successfully against many mammals. The major factor limiting the wider use of wildlife fences is their cost, which varies depending on many factors such as topography, type of fence and the species it is designed to contain (Kenya Wildlife Service, 1996).

Electric fencing: Electric fencing is a more sophisticated and efficient solution. It is more durable, due to the reduced physical pressure from animals; it deters a wider range of species; and it is more aesthetically appealing. However, the cost of installation and maintenance is higher than for simple fences (Hoare, 1992).

\section{Wildlife (wild animal) management Non-lethal control}

The non-lethal methods such as translocation, acoustic deterrents (scaring noise), visual deterrents (colored cloths, flames, smokes of fires), olfactory deterrents (chemicals produce unpleasant and painful smells such as burning rubber, car oil, tobacco) and taste deterrents (such as sisal, chili or green pepper, tea, ginger or oilseed)can be effective if rural people living around reserve areas are involved in their implementation and are also involved in the conservation and sustainable utilization of wildlife resources (Frank and Woodroffe, 2002).

Translocation: is non-lethal control method consists of moving a certain number of animals from a problematic zone to a new site. In spite of the risk of exporting the problem to another site, it may be a practical and politically correct approach in some cases, especially where suitable habitats with territorial vacancies are available (Simonetti, 2011).In some situations, translocation can be a pre-emptive action before human wildlife conflict occurs (Conover, 2002). For instance, the presence of a lion in cattle ranching area or large crocodiles in water bodies close to human habitation can often be detected before the animals have caused a problem. These potential problem causing animals can then be removed and Trans-located before they kill livestock or people (Omondiet al., 2002).

\section{Lethal control}

Well managed lethal control has the potential to reduce threats to human lives and livelihoods without causing serious extinction risks (Frank and Woodroffe, 2002). With lethal control it is obviously desirable to focus on those individuals actually causing the problem or at least to target the group of animals whose home range includes the site where the problem is occurring (Stander, 2000).

Indeed, lethal control programmes must be undertaken with care given the technical challenges surrounding the number and type of animals killed, as well as political and moral issues concerning who is allowed to kill animals and how(Loveridge, 2002).The study by Linnellet al. (2005) indicated if lethal control is to foster coexistence of people and wildlife; it must reduce the impact of wildlife on people or raise public tolerance for damage without a significant reduction in the viability of wildlife populations. According to the proportion of removed animals and the selectivity used to remove individuals the deliberate removal programmers can be Eradication campaigns, Cullingprograms, Public hunts and Selective removal of wildlife (Linnellet al., 2005).

Eradication campaigns: aim to extirpate problem wildlife from entire regions by all means available. Depending on the intensity of effort and the resilience of the target species, extirpation campaigns may produce local, regional or global extinctions (Hoare, 2001).

Culling programmes:aim to reduce subpopulations of problem wildlife around specific sites of anticipated conflict under the assumption that reducing wildlife populations will reduce conflicts (HUSA, 2012 and Hoare, 1992).

Public hunts: in contrast to eradication often include regulations governing the actors, location, timing or method of killing animals, in addition to limits on the number and type of animals that can be killed. In contrast to government-sponsored culling programmes, private citizens usually pay or volunteer to remove wildlife usually without reference to the location of past conflicts (Hanks, 2006).

Selective removal of wildlife: is aimed specifically at the individuals suspected to have damaged property. Hence the location, methods and target are specified narrowly which usually means that only trained authorities 
kill wildlife (Hoare, 1992).

\section{Environmental Management \\ Increasing alternative crops}

The use of diversionary tactics, i.e. providing an alternative source of food or water, in an attempt to lessen competition of wildlife with people for crops or water is a less commonly used management approach(Hanks, 2006). Diversionary fields have reportedly been used successfully to reduce crop damage (Conover, 2002).However the improvement of habitats in protected areas and their buffer zones could retain wildlife longer and thus decrease the intensity of crop-raiding (Mabunda, 2005).

\section{Preventing poaching and commercial}

Poaching has become one of the ever growing problems facing wildlife conservation and a potential threat to wildlife tourism development efforts. In Cameroon for example, during a single week, at least 86 elephants (among them 33 pregnant females and their calves) were slaughtered and over the first three months of 2012 more than 100 elephants were slain atBoubaNdjida National Park (Quarterman, 2013). Henk (2005) identified three types of poaching behaviors in Sub-Saharan Africa; subsistence, trophy and commercial. Subsistence poachers are those who hunt wildlife illegally as food sources.

To maintain adequate populations and restore the natural balance between predator and prey preventing poaching and commercial harvest is very important (Polisaret al., 2003). This can also result preventing carnivores from relying on a diverse diet that includes domestic livestock (KWS, 2005).

The collection and commercialization of ivory within national parks and wildlife reserves is absolutely forbidden (Henk, 2005).In Ethiopia anyone hunting without a valid permit, hunting outside the restrictions established in permit, or failing to submit the slaughter report required by Regulation No. 163/2008 is subject to imprisonment from one to five years and/or a fine from 5000 to 30,000 birr (Federal NegaritGazeta of FDRE, 2008).

\section{Providing Alternative water sources for wildlife species}

Water management can be a good means of reducing wildlife populations when increasing numbers generate human-wildlife conflict. The closure of water points in protected areas on a temporary or permanent basis has been suggested as a possible means of decreasing the number of wildlife to make longer journeys to feed and drink while increasing mortality in younger individuals (Mabunda, 2005).

In habitats where natural water source is limited providing supplemental water to wildlife is very important. Many people mistakenly believe that water sources suitable for livestock are also suitable for wildlife (Jontos, 2004). Unfortunately that is not always the case, particularly for young wildlife and many bird species. Marsh or wetland restoration or development can provide supplemental water in the form of shallow wetlands for wetlanddependent wildlife, even in areas where inadequate water does not limit wildlife (Conover, 2002).

\section{Land use-planning}

Land-use planning is a basic human-wildlife conflict management strategy which offers possibly the best chance of overall and long-term success (WWF SARPO, 2005). Unlike strategies of protection and mitigation, it tackles the root of the problem. It is therefore a preventive approach designed to alleviate human-wildlife conflict by creating landscapes in which people and wildlife can co-exist and have as little negative impact on each other as possible (Muruthi, 2005). Land-use planning is typically a long-term process that requires government support, legislation and policy changes (Mohammed Abdiet al., 2003).

If environmental impact assessment is not well planned and prepared, development itself can damage or destroy ecosystems, making it more difficult for many native species to survive (IUCN, 1994). All animal species require certain habitat features to survive. For example, a diverse wildlife population depends upon the natural ecosystems found in most undeveloped areas. Those species able to survive in urban settings may thrive, but the rest are forced to find new territory to survive. When a species' habitat is separated by such distances that make movement from one area to another impossible, the impacts on the health of the population are significant and reduce a species ability to reproduce (Beyer et al., 2010).

\section{Zoning around protected areas}

Zoning is geographically differentiated land management where different forms of potentially conflicting land use are given priority in different places is widely used for wildlife conservation in the creation of national parks, hunting areas and other protected areas (Loveridge, 2002).The basic concept is to reduce overlap between large carnivores and sources of conflict through complementary use of different management tools. If zoning is used, it is essential to scale management zones to the size of the biological process that they are designed to manage (Linnellet al., 2005). 


\section{The way forward}

This section offers some strategies that can be employed to overcome the problem of habitat destruction and other forces threatening wildlife resources of the country.

- Clarify the respective conservation roles of regional and federal governments, as well as the private sector

- Adopt the poverty reduction policies/strategies that are conservation-friendly

- Make human population growth a priority agenda

- $\quad$ Provide adequate conservation status to critical wildlife areas

- Discourage policies, land uses and projects likely to have adverse impacts on habitats

- Enhance conservation education and research

- Involve local communities on land use planning and provide adequate conservation incentive

- Enhance employment opportunities in and around protected areas

\section{REFERENCES}

Adams, W.A.2003.Nature and the colonial mind. In Decolonizing Nature: Strategies for Conservation in the Postcolonial Era. W.A. Adams and M. Mulligan, eds. London: Earth scan.

Adams, W.M. and Hutton, J. 2007. People, parks, and poverty: political ecology and biodiversity conservation. Conservation Society, 5: 147-183.

Africa Parks. 2005. Foundation Omo People in danger of denial of access or displacement Native Solutions to Conservation Refugees website

AlamnehAmare. 2015. Conservation Challenges of Gibe Sheleko National Park, Southwestern Ethiopia. Natural Resources, 6: 286-289.

AlamnehAmare. 2015. Wildlife Resources of Ethiopia: Opportunities, Challenges and Future Directions: From Ecotourism Perspective: A Review Paper. Natural Resources, 6: 405-422.

AnagawAtickem, AfwerkBekele, and Williams, S.D. 2010. Competition between domestic dogs and Ethiopian wolf (Canissimensis) in the Bale Mountains National Park, Ethiopia.African Journal of Ecology, 48(2): 401-407.

Anderson, D. and Grove, R. 1987. The scramble of for Eden: Past, present and future in African Conservation; People, Policies and Practice. Cambridge University Press. Cambridge, U.K.

Astrid, M. Vreugdenhil, TamiratTilahun, AntenehShimelis and ZelealemTefera. 2012. Gap Analysis of the Protected Areas System of Ethiopia. Ethiopian Wildlife Conservation Authority with funding from the GEF / UNDP/ SDPASE project. Addis Ababa.

Baldus, R. 2005. Community in Tanzania to harvest problem crocodiles.African Indaba e-Newsletter, 3(3): 20p.

Barnes, D., Galgani, F., Thompson, R. and Barlaz, M. 2009.Accumulation and fragmentation of plastic debris in global environments. Philosophical Transactions of the Royal Society B. 364: 1985-1998.

Barua, M., Bhagwat, S. and Jadhav, S. 2013. The hidden dimensions of human-wildlife conflict: health impacts opportunity and transaction costs. Biological Conservation, 157: 309-316.

Beyer, H., Haydon, D., Morales, J., Frair, J. and Hebblewhite, M. 2010.The interpretation of habitat preference metrics under use-availability designs. Philos Trans R SocLond B BiolSci, 365: 2245-2254.

Bolen, G. and Robinson, W. 2003.Wildlife Ecology and Management 5th edition, Prentice Education Inc., USA.

Butler, J. 2000. The economic costs of wildlife predation on livestock in Gokwe communal land, Zimbabwe.African Journal of Ecology, 38(1): 23-30.

Conover, M. 2002. Resolving human-wildlife conflicts: the science of wildlife damage management.New York, USA, Lewis Publishers.

DemekeDatikoHansilo and Lemma Tiki. 2017. Challenges of human settlement on wildlife in Bale Mountains National Park, Southeast Ethiopia. International Journal of Biodiversity and Conservation, 9(4): 107-114.

EBI. 2014. Ethiopia's Fifth National Report to the Convention on Biological Diversity. Ethiopian Biodiversity Institute, May 2014, Addis Ababa, Ethiopia.

Elephant Pepper Development Trust. 2006. Community-based problem animal control: livelihood security for people living in elephant range. A training manual, version 4.1. Livingstone, Zambia.

Establishment Regulations No. 163/2008.AddisAbaba, Ethiopia

EWCA. 2012. National Action Plan for the Conservation of Cheetahs and African Wild Dogs in Ethiopia, Addis Ababa, Ethiopia.

Federal NegaritGazeta of FDRE, 2008.Ethiopian Wildlife Development and Conservation Authority.

Fonturbel, F.andSimonetti, J. 2011. Translocations and human-carnivore conflicts: problem solving or problem creating? Wildlife Biology 17(2), 217-224.

Frank, L. and Woodroffe, R. 2002. Managing predators and livestock on an East African rangeland.Modeling conflict, Wildlife Conservation Research Unit, Oxford, UK.12-17.

Gehring, T., VerCauteren, K., and Landry, J. 2010. Livestock protection dogs in the 21st century: Is an ancient 
tool relevant to modern conservation challenges? BioScience, 60(4): 299-308.

GirmaMengesha, YosefMamo and AfewerkBekele. 2011. A comparison of terrestrial bird community structure in the undisturbed and disturbed areas of the AbijataShalla lakes national park, Ethiopia. International Journal of Biodiversity and Conservation, 3:389-404.

Hanks, J. 2006. Mitigation of human-elephant conflict in the Kavango-Zambezi Transfrontier Conservation Area through Community Based Problem Animal Control, with particular refrence to the use of chilli peppers. Report prepared for Conservation International.

Hawley, J., Gehring, T., Schulz, R., Rossler, S. and Wydeven, A. 2009. Assessment of shock collars as nonlethal management for wolves in Wisconsin. Journal of Wildlife Management, 73: 518-525.

Henk, D. 2005. The Botswana defense force and the war against poachers in Southern Africa. Small Wars and Insurgencies, 16(2): 170-191.

Hobbs, R. 2002. Habitat networks and biological conservation.Applying landscape ecology in biological conservation. New York. Springer-Verlag, 150-170.

Hofmeyr, M. 2004. Translocation of elephant from the Kruger National Park to the Limpopo National Park as part of the initial development of the Greater Limpopo Transfrontier Park. Abstract for the EMOA Elephant Symposium, Bakgatla Camp, Pilanesberg National Park, September 2004, 13-17.

Hulme, D. and Murphree, M. 2001. African Wildlife and Livelihoods: The Promise and Performance of Community Conservation. Oxford, U.K.,November 2009, Addis Ababa,Ethiopia.

HUSA. 2012. Hunting for Sustainability in Africa (HUSA).

IBC (Institute of Biodiversity Conservation). 2009. Ethiopia's $4^{\text {th }}$ country report on convention on Biological Diversity.

IUCN. 1994. Guidelines for Protected Area Management Categories. IUCN, Cambridge, UK and Gland, Switzerland.

Jontos, R. 2004. Vegetative buffers for water quality protection: An introduction and guidance document. Connect cut Association of Wetland Scientists White Paper on Vegetative Buffers. Draft version 1.0. 22pp.

Kenya wildlife service. 1996. Wildlife-human conflicts, sources, solutions and issues. Available at: www.safariweb.com/kwild/wildlife.htm.

Kideghesho, J. 2001. Mitigating the loss of wildlife habitats in Tanzania: Current and future strategies. Tanzania Journal of Forestry and Nature Conservation, 74:149-161.

La Grange, M. 2005. Problem lion control - methods and general observations related to the control of problem lions. In Wildlife management, Vol. II, Problem animal control. Report to the International Foundation for the Conservation of Wildlife (Fondation IGF), Harare, Zimbabwe.

LeykunAbune. 2003. The Challenges of Conserving Ethiopian Wildlife: Ethiopian Wildlife and Natural History Society. Walia, 21: 12-14.

Lilieholm, R. and L. Romney. 2000. Tourism, national parks, and wildlife. In Tourism and National Parks: Issues and Implications. R.W. Butler and S.W. Boyd, eds. New York: John Wiley and Sons, 137-151.

Lindsey, P. 2008. Trophy Hunting in Sub-Saharan Africa: Economic Scale and Conservation Significance. In: Baldus, R.D., Damm, G.R. and Wollscheid, K., Eds., Best Practices in Sustainable Hunting, 41-47.

Linnell, J. Nilsen, E., Lande, U., Herfindal, I., Odden, J., Skogen, K., Andersen, R. and Breitenmoser, U. 2005. Zoning as a means of mitigating conflicts with large carnivores: principles and reality. In R. Woodroffe, S. Thirgood\& A.R. Rabinowitz, eds. People and wildlife: conflict or coexistence?. Cambridge, UK, Cambridge University Press, 162-175.

Mabunda, D. 2005. Report on the elephant management strategy. Report to the Minister: Environmental Affairs and Tourism on developing elephant management plans for national parks with recommendations on the process to be followed.Pretoria, South Africa, South African National Parks.

Madhusudan, M. 2003. Living amidst large wildlife: livestock and crop depredation by large mammals in the interior villages of Bhadra Tiger Reserve, South India.EnvironmentalManagement, 31(4): 466-475.

Marino, J., Randall, D., Haydon, D., Sillero-Zubiri, C., Knobel, D., Tallents, L., Macdonald, D. and Laurenson, M. 2006.An integrated disease management strategy for the control of rabies in Ethiopian wolves.Biological Conservation, 131(2): 151-162.

Masanja, G. 2014. Human Population Growth and Wildlife in Ugalla Ecosystem, Western Tanzania.Journalof Sustainable Development Studies, 2: 192-217.

MeseleYihune. 2008. Human-Gelada Baboon Conflict in and around the Simien Mountains National Park, Ethiopia. African Journal of Ecology, 19: 1-7.

Mohammed Abdi, YirmedDemeke, MengistuWondafrash, BekeleJembere, AlmazBayero and Azam Yusuf. 2003. Terrestrial Wild Animals and Protected Areas of Ethiopia prepared for Biodiversity Strategy and Action Plan Project (BSAP).

Mudgal, S., Lyons, L., Bain, J. 2011. Plastic Waste in the Environment: Revised Final Report for European $\begin{array}{lllll}\text { Commission } & \text { DG } & \text { Bnvironment. }\end{array}$ 
http://www.ec.europa.eu/environment/waste/studies/pdf/plastics.pdf

Murphy, C. 2007. Community-based crocodile management. Travel News Namibia. Available at: www.travelnews.com.na/index.php?fArticleId=1042.

Murray, F. and Cowie, P. 2011. Plastic contamination in the decapod crustacean Nephropsnorvegicus(Linnaeus, 1758)MarinePollutionBulletindoi:10.1016/j.marpolbul.2011.03.032.

Muruthi, P. 2005. Human wildlife conflicts: lessons learned from AWF's African heartlands. AWF Working Papers.Nairobi, Kenya, African Wildlife Foundation.

Ndibalema, V. 2010. Conservation of African national Parks, Challenges from migratory mammals. In: RoskaftE,Gereta, J.E. Eds, Conservation of NaturalResources, some African and Asian Examples. Tapir Academic Press, Trondheim.

Neumann, R. 1998. Imposing Wilderness: Struggles over Livelihood and Nature Preservation in Africa. Berkeley: University of California Press.

Newmark, W., Manyanza, D., Gamassa, I.andSariko, H . 1994. The conflict between wildlife and local people living adjacent to protected areas in Tanzania: Human density as a predictor. Conservation Biology, 8: $249-255$.

Ogada, M., Woodroffe, R., Oguge, N. and Frank, G. 2003.Limiting depredation by African carnivores: the role of livestock husbandry. Conservation Biology, 17(6): 1521-1530.

Omondi, P., Wambwa, E., Gakuya, F., Bitok, E., Ndeere, D., Manyibe, T., Ogoloa, P. and Kanyingi, J. 2002.Recent translocation of elephant family units from Sweetwaters Rhino Sanctuary to Meru National Park, Kenya.Pachyderm, 32: 39-48.

Parsons, G. 2002. The essence of wildlife management.Wildlife Society Bulletin, 30(2): 585-593.

Philip, A., Candy, A., Claudio,Z. and Nigel, L. 2001. Impact of livestock and settlement on the large mammalian wildlife of Bale Mountains National Park, southern Ethiopia.Wildlife Conservation Research Unit, Department of Zoology, University of Oxford.Biological Conservation, 100: 307-322.

Polisar, J., Maxit, I., Scognamillo, D., Farrell, L., Sanquist, M.E and Eisenberg J.F. 2003. Jaguars, pumas, their prey base, and cattle ranching: ecological interpretations of a management problem. Biological Conservation, 109(2): 297-310.

Quigley, H. and Herrero, S. 2005. Characterization and prevention of attacks on humans. People and wildlife: conflict or coexistence? Cambridge, UK, Cambridge University Press.

Riley, S., Decker, D., Carpenter, L., Organ, J., Siemer, W., Mattfeld, G. and Sekercioglu, C.H. 2012.Bird functional diversity and ecosystem services in tropical forests, agro forests and agricultural areas.Journal of Ornithology, 153:153-161.

Sheavly S.B. (2005). Sixth Meeting of the UN Open-ended Informal Consultative Processes on Oceans \& the Law of the Sea.Marine debris - an overview of a critical issue for our oceans. June 6-10, 2005. http://www.un.org/Depts/los/consultative_process/consultative_process.htm

Sinclair, A. 1995.Serengeti past and present. In Sinclair, A.R.E. and Arcese, P. (Eds) Serengeti II: Dynamics, Management and Conservation of an Ecosystem . Chicago: The University of Chicago Press.

Stander, P. 2000. Conservation of lions and other large carnivores in the Kunene region, Namibia.African Lion News, 2: 8-9.

Stanley, M., Makindi, N., Mutinda, W. and Olekaikai, L. 2014. Human-Wildlife Conflicts: Causes and Mitigation Measures in Tsavo Conservation Area, Kenya, Abdillahi A. International Journal of Science and Research , 3: 2319-7064.

Stewart, O., Lewis, H. and Anderson, M. 2002. Forgotten Fires: Native Americans and the Transient Wilderness.University of Oklahoma Press. Norman.

Tedla, S. 1995. Protected areas management crises in Ethiopia.Journal of the Ethiopian Wildlife and Natural History Society, 16p.

Tefera, M. 2011.Wildlife in Ethiopia: Endemic Large Mammals. Current Zoology, 6: 108-116.

TewdrosKumsa. 2006. Human-Wildlife Conflict and Population Status of Swayne's Hartebeest (Alcelaphusbuselaphusswaynei) in Senkele Swayne's Hartebeest Sanctuary. Master's Thesis, Addis Ababa University, Addis Ababa.

Treves, A. and Karanth, K. 2003. Human carnivore conflict and perspectives on carnivore management worldwide.Conservation Biology, 17(6): 1491-1499.

Vial, F., Macdonald, D. and Haydon, D. 2011. Response of endemic afroalpine rodents to the removal of livestock grazing pressure.Curr. Zool., 57: 741-750.

WeldemariamTesfahunegnyBezabh. 2006. A guide to a complete annotated checklist of the birds of Ethiopia.

Whitesell, S., Lilieholm, R. and Sharik, T. 2002. A global survey of tropical biological field stations. BioScience, 52:55-64

William, S., Fensham, R., Fairfax, R. and Archer, S. 2005. Rainfall, land use and woody vegetation cover change in semi-arid Australian savanna. Journal of Ecology, 93: 596-606. 
Wolff, J. 1961. Wildlife in Ethiopia.Ethiopian Forestry Review, 2: 3-13.

Woodroffe, R., Frank, L., Lindsey, P., Ranah, S. and Romañach, S. 2007. Livestock husbandry as a tool for carnivore conservation in Africa's community rangelands: a case-control study. Biodiversity Conservation, 16(4): 1245-1260.

WWF SARPO. 2005. Human wildlife conflict manual. Harare, Zimbabwe, WWF Southern African Regional Programme Office (SARPO).

Yalden,D. and Largen, M.1992. The endemic mammals of Ethiopia.Mammals review, 22: 115-150.

Yarrow, G. 2009. Wildlife and Wildlife Management. Fact Sheet: 36.

YosefMamo. 2014. Attitudes and perception of local peoples towards benefits and conflicts they get from Bale Mountains National Park and Mountain Nyala (Tragelaphusbuxtoni), Ethiopia. International journal of biodiversity and conservation, 7(1): 28-40.

Young. 2012. Ethiopian Protected Areas: A “Snapshot”. Word Press, Addis Ababa, 23.

ZelealemTefera and Williams,N. 2005.Indigenous common property resource management in the Central Highlands of Ethiopia.Human Ecology, 33: 539-563.

ZerihunGirma, Yosef,Mamo and MateosErsado. 2012. Species composition, distribution and relative abundance of larger mammals in and around wondogenet forest patch, southern Ethiopia. Asian Journal of Applied sciences, 5(8): 538-551. 